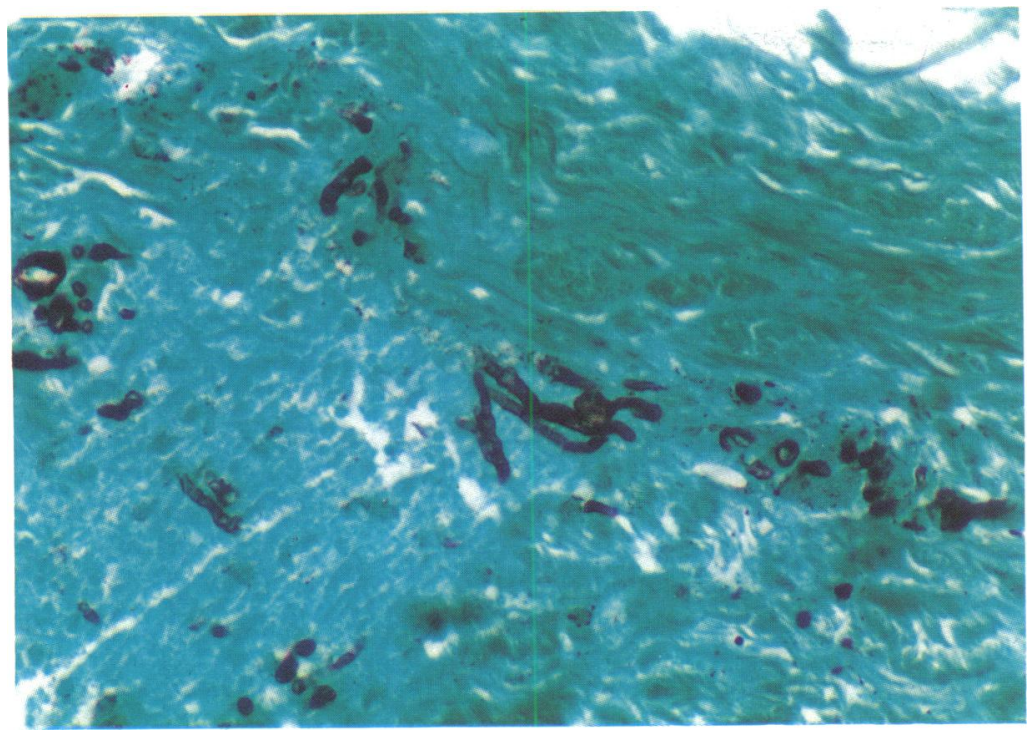

Figure 4 Hyphae in a section of sclera obtained at the time of sclerectomy (Gomori-methenamine-silver stain, $\times 22$.)

scleritis have been reported following pterygium surgery, ${ }^{3}$ scleral buckling procedures ${ }^{4}$ and cataract surgery. ${ }^{5}$ Trauma has been described as a cause for mycotic scleritis, ${ }^{67}$ but our patient did not recall any eye injury. Although these reported cases refer to exogenous infections, with agents other than $A$ niger, they do show similarities to our case. Clinically, severe headaches and periocular pain are common findings, with symptoms that wax and wane following use of corticosteroids. In all cases, a delay in diagnosis was encountered. We cannot exclude the possibility that an infection was introduced at the time of the subconjunctival injections of corticosteroids, but the scleritis was present before the first injection and the original presentation did not differ significantly from subsequent recurrences. Furthermore, the location of the injection was away from the location of the scleritis. As mentioned above, apart from trauma and surgery, a third source of infection can be endogenous spread from another infected site for example, following injecting drug use. ${ }^{12}$ In spite of an extensive examination, no source of infection could be identified in our patient. However, since our patient had a history of drug misuse, such an endogenous route related to drug misuse cannot be excluded. Since she had also been treated for automutilation of the breast, automutilation of the eye as a source of Aspergillus infection may have led to a primary scleritis, followed by a mycotic endophthalmitis. The isolation of a concomitant second infectious agent (the streptococcal infection) could also be due to manipulation of the ocular surface. It could, however, also be an opportunistic infection on an otherwise already traumatised ocular surface. Our conclusion is that despite the relatively rare occurrence infection with Aspergillus should be regarded as a possible cause of any unusual protracted scleritis.

The clinical photographs were taken by $\mathrm{Mr}$ Anthony Cubillas.

1 Stenson S, Brookner A, Rosenthal S. Bilateral endogenous necrotizing scleritis due to Aspergillus oryzae. Ann Ophthalmol 1982; 14: 67-72.

2 Doft BH, Clarkson JG, Rebell G, Forster RK. Endogenous Aspergillus endophthalmitis in drug abusers. Arch Ophthalmol 1980; 98: 859-62.

3 Margo CE, Polack FM, Mood CI. Aspergillus panophthalmitis complicating treatment of pterygium. Cornea 1988; 7: 285-9.

4 Lincoff HA, McLean JM, Nano H. Scleral abscess: I. A complication of retinal detachment buckling procedures. complication of retinal detachm

5 Carlson AN, Foulks GN, Perfect JR, Kim JH. Fungal scleritis after cataract surgery. Successful outcome using itraconazole. Cornea 1992; 11: 151-4.

6 Köllner H. Schimmelpilzerkrankung der Sklera. $Z$ Augenheilkd 1906; 16: 441-7.

7 Hemady R, De la Maza MS, Raizman MB, Foster CS. Six cases of scleritis associated with systemic infection. $A m \mathcal{F}$ Ophthalmol 1992; 114: 55-62.
Ophthalmology

\section{Department, Princess}

Alexandra Eye Pavilion,

Royal Infirmary,

Chalmers Street,

Edinburgh EH3 9HA

Z Butt

Neuropathology

Laboratory, Western

General Hospital,

Edinburgh

$\mathbf{J}$ W Ironside

Correspondence to:

Dr Z Butt.

Accepted for publication

22 February 1994

\title{
Superficial epithelioid schwannoma presenting as a subcutaneous upper eyelid mass
}

\author{
Z Butt, J W Ironside
}

We describe a case of superficial epithelioid schwannoma presenting as a mass in the superotemporal quadrant of the orbit. This was treated by local excision with no evidence of recurrence or metastases on follow up. To the best of our knowledge, this is the first case report of the tumour in this particular area.

\section{Case report}

A 55-year-old woman presented to our casualty department in 1989 with a 2 year history of an asymptomatic enlarging mass along the temporal aspect of her left upper eyelid. There was no significant medical or ocular history and the patient displayed none of the stigmata of neurofibromatosis.

On examination, corrected visual acuity was $6 / 6$, N5 right eye and 6/9,N5 left eye. Pupils were reactive to light, she had a full range of extraocular movements and there was no proptosis. Her discs were normal. She had a $1 \mathrm{~cm}$ diameter smooth firm mobile mass along the superotemporal quadrant of her orbit. Posterior 


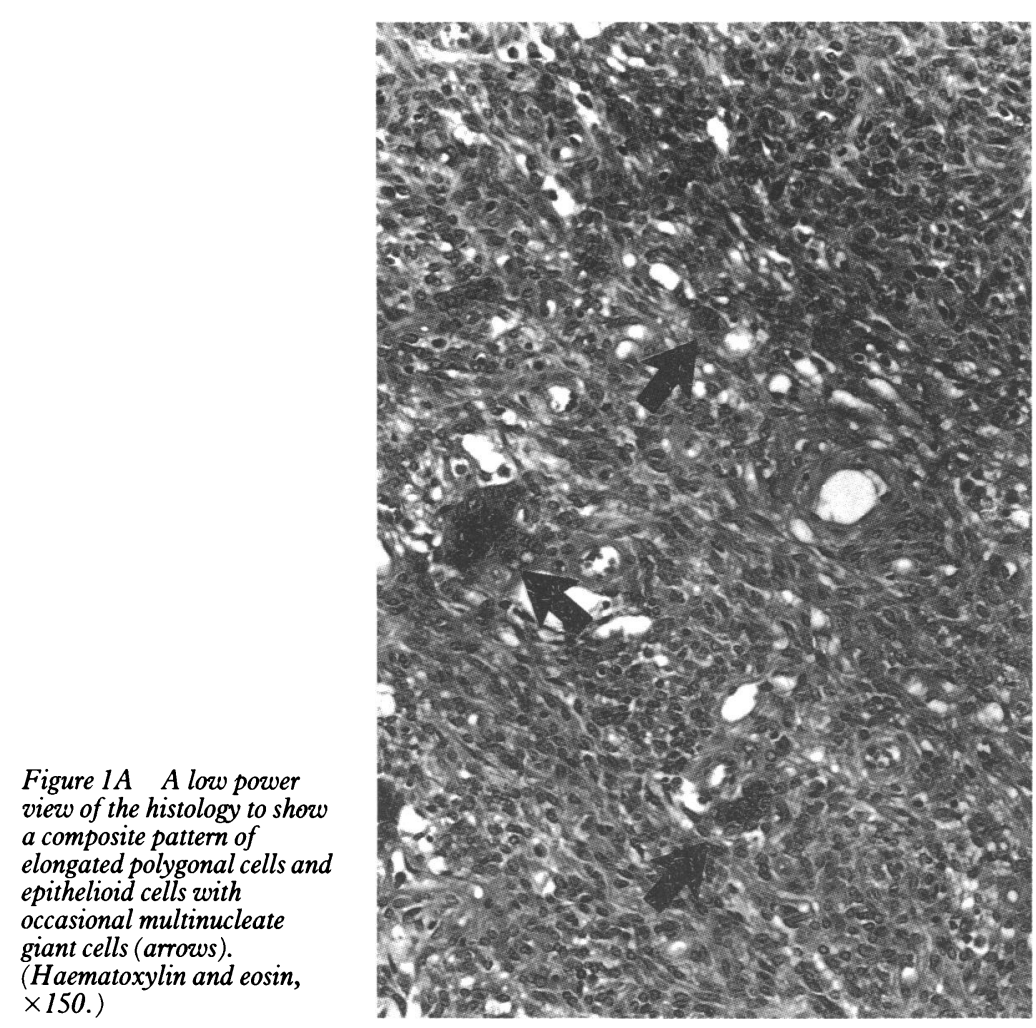

(Haematoxylin and eosin $\times 150$.)

Figure $1 B$ The blood vessels and tumour cells are surrounded by a delicate interweaving reticulin framework. (Gordon and Sweet stain for reticulin, $\times 100$.)
HISTOPATHOLOGY

The specimen was an apparently encapsulated smooth surfaced nodule measuring $8 \times 5 \times 4 \mathrm{~mm}$. The lesion had been incised before receipt, demonstrating a solid grey/white cut surface. Histological examination showed a neoplasm with a composite pattern comprising spindle cells arranged in irregular bands and a population of larger epithelioid cells in solid sheets, with occasional large multinucleate cells (Fig 1). An extensive reticulin framework was present, with a predominantly pericellular distribution (Fig 1). The epithelioid cells contained abundant cytoplasm with well defined cell boundaries (Fig 2). Numerous thin walled capillaries were present throughout the tumour, but there was no sign of endothelial hyperplasia or haemorrhage. Occasional mitotic figures were identified (less than one mitotic figure per 10 high power fields). Although the tumour appeared encapsulated on naked eye inspection, on microscopy the tumour boundary was irregular with infiltration of the surrounding fibrous pseudocapsule.

Stains for neutral and acidic mucins and melanin were negative. Immunocytochemistry showed a positive reaction for $\mathrm{S} 100$ protein in polygonal and epithelioid cells (Fig 2B). Occasional large epithelioid cells also gave a positive reaction using an antibody to epithelial membrane antigen, but immunocytochemistry for cytokeratins was negative. Many of the tumour cells and vascular endothelial cells gave a positive staining reaction for vimentin, but no reaction was observed on immunocytochemistry for glial fibrillary acid protein, neurofilament protein, desmin, myoglobin, and the leucocyte common antigen. Electron microscopy showed irregular

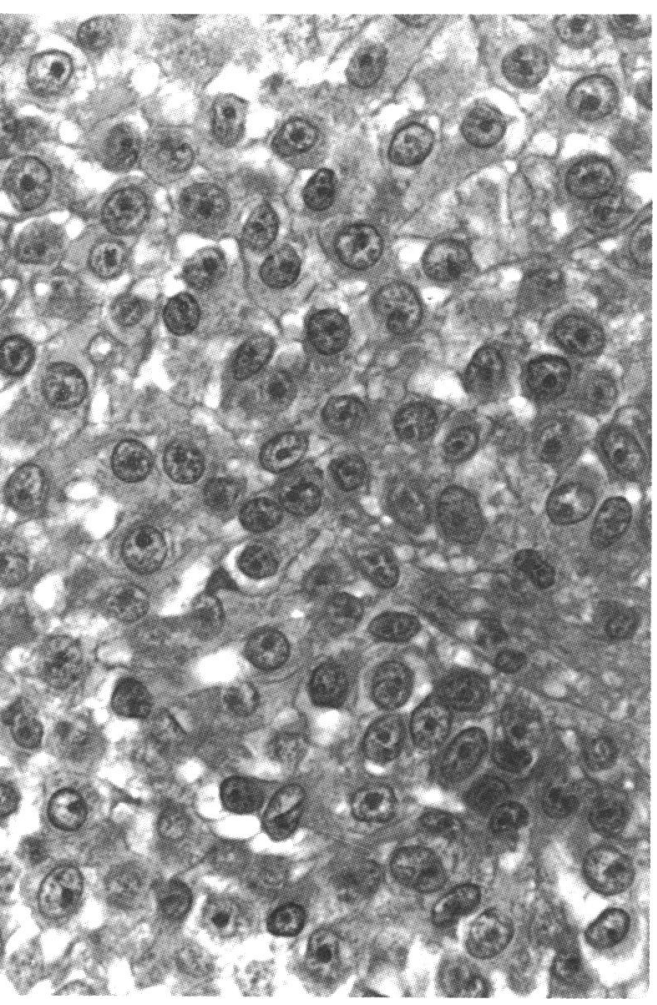

Figure 2A The epithelioid cell population comprises cells with a large nucleus, prominent nucleolus, and well defined cell boundary. Occasional cells contain abundant pale cytoplasm. (Haematoxylin and eosin, $\times 480$.) 


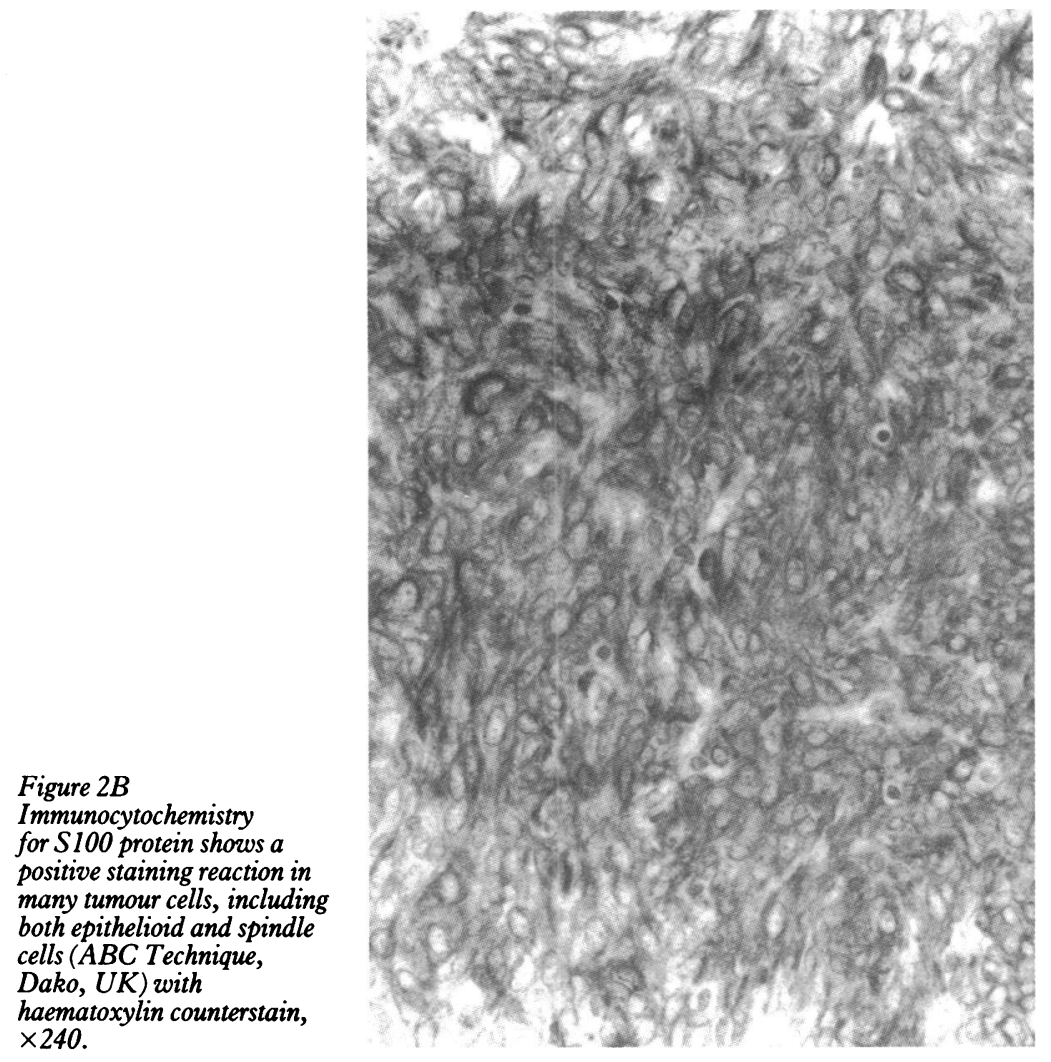

polygonal cells surrounded by an abundant basement membrane. A few poorly formed intercellular junctions were noted, but no true desmosomes were identified. No premelanosomes, keratin filaments, muscle filaments, or neurosecretory granules were present in the tumour cell cytoplasm.

\section{Comment}

Epithelioid schwannoma is a rare variant of peripheral nerve sheath tumour and usually presents as an asymptomatic mass either in superficial (dermis or subcutaneous) tissue or deep soft tissue of the extremity. Superficial epithelioid schwannoma in the head and neck region therefore represents an uncommon variant of a rare tumour. ${ }^{1-4}$ The majority of superficial lesions are curable if wide local excision is accomplished expeditiously. ${ }^{5}$ Those in deep tissues, however, tend to be highly malignant and should be treated aggressively with possible adjuvant therapy. ${ }^{5}$

The histological appearances of epithelioid schwannomas are variable, and in the past may have been confused with melanoma or metastatic carcinoma. ${ }^{4}$ The presence of epithelioid cells in a vague nodular pattern (as in this case) is characteristic. ${ }^{4}$ The immunocytochemical and ultrastructural features in this case are also characteristic and enable a distinction from metastatic carcinoma and melanoma. ${ }^{46}$ Epithelioid schwannomas are uncommon tumours; previous literature reports indicate that these are fully malignant neoplasms and warrant aggressive treatment. ${ }^{1-6}$ Mitotic activity and other histological features indicating malignancy are not uniformly present; the histological appearance cannot therefore be relied upon as a predictor of biological behaviour. ${ }^{46}$

Our case has behaved in a benign fashion with complete local excision and no evidence of recurrence or metastasis on a 2 year follow up. Accurate histological diagnosis and early complete wide excision of superficial epithelioid schwannoma should be the objectives in managing this tumour.

1 Bleach NR, Keen CE, Dixon JA. Superficial malignant schwannoma on the face: a case for early radical surgery. $\mathcal{F}$ Laryngol Otol 1989; 103: 316-8.

2 Morgan KG, Gray C. Malignant epithelioid schwannoma of superficial soft tissue? A case report with immunohistology and electron microscopy. Histopathology 1985; 9: 765-75.

3 Jacinto CM, Grant-Kels JM, Knibbs DR, Daman LA, Piorkowski RJ. Malignant primitive neuroectodermal tumor presenting as a scalp nodule. Am $\mathcal{f}$ Dermatopathol 1991; 13: 63-70.

4 Enzinger FM, Weiss SW. Soft tissue tumors. 2nd ed. St Louis: Mosby, 1988: 798-801.

5 Alvira MM, Mandybur TI, Menefee MG. Light microscopic and ultrastructural observations of a metastasizing malignant and ultrastructural observations of a metastasizing masc

6 Gosh BC, Gosh L, Huvos AG, Fortner JG. Malignant schwannoma: clinicopathologic study. Cancer 1973; 31: $184-90$.

\section{Department of Ophthalmology M Mulhern}

G O'Connor

Department of Pathology C Keohane

Cork Regional Hospital, Wilton, Cork, Ireland

Correspondence to: Mr G O'Connor

Accepted for publication 7 March 1994
Duane's retraction syndrome (DRS) is a congenital ocular motility disorder of neurogenic origin but of unknown aetiology. Clinically there is deficiency or loss of abduction and adduction and there may also be palpebral fissure diminution and globe retraction on attempted adduction.
Upshooting or downshooting of the globe may occur when adduction is attempted. DRS was first described in $1887^{\prime}$ and early reports suggested a myogenic disorder; however, absence of the abducens nerve and nucleus with innervation of the affected lateral rectus muscle by the 